\title{
Front Matter: Volume 7284
}

, "Front Matter: Volume 7284," Proc. SPIE 7284, 4th International Symposium on Advanced Optical Manufacturing and Testing Technologies: Design, Manufacturing, and Testing of Micro- and Nano-Optical Devices and Systems, 728401 (18 May 2009); doi: 10.1117/12.834211

SPIE Event: AOMATT 2008 - 4th International Symposium on Advanced Optical Manufacturing, 2008, Chengdu, Chengdu, China 


\section{PROCEEDINGS OF SPIE}

\section{4th International Symposium on Advanced Optical Manufacturing and Testing Technologies Design, Manufacturing, and Testing of Micro- and Nano-Optical Devices and Systems}

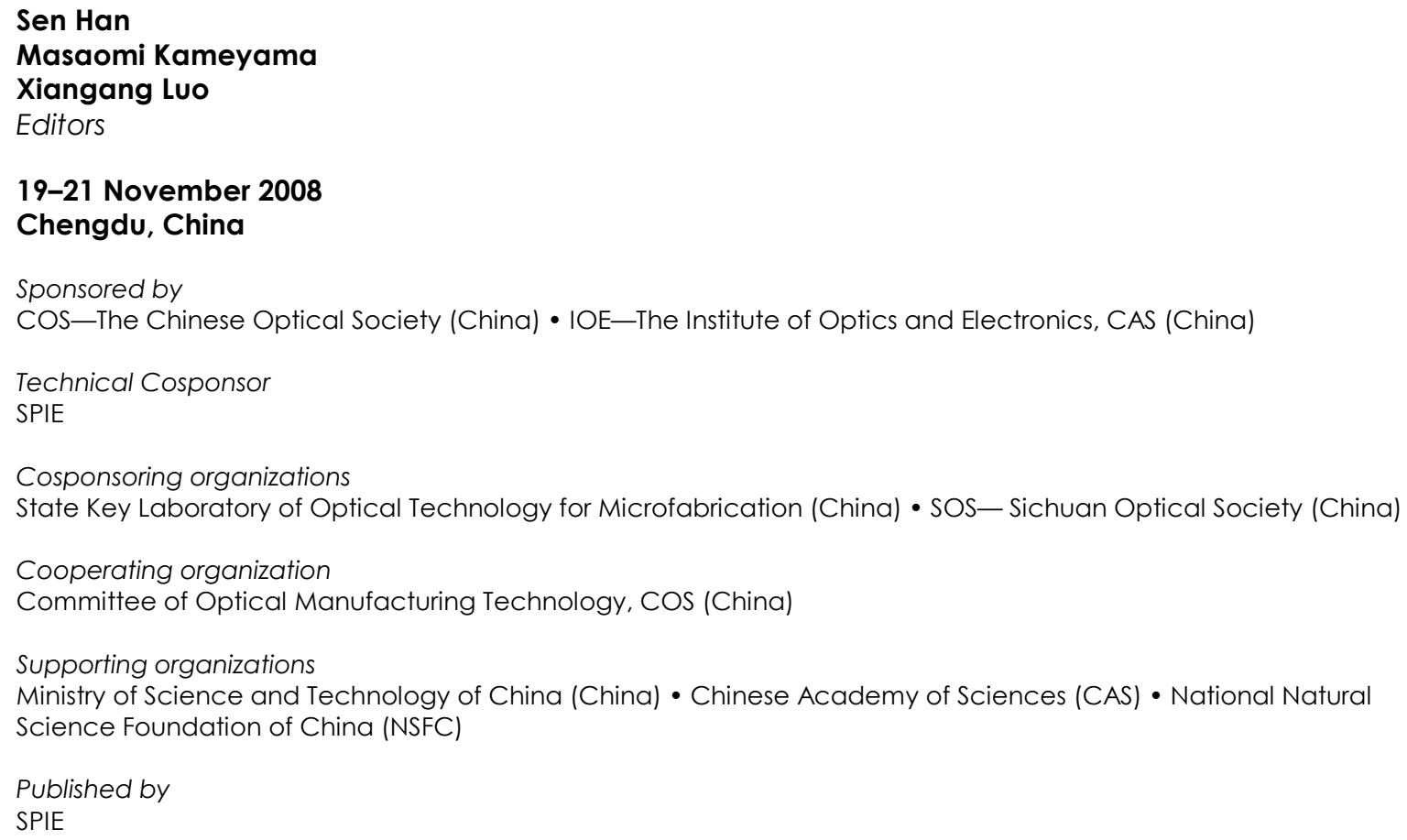

Volume 7284 
The papers included in this volume were part of the technical conference cited on the cover and title page. Papers were selected and subject to review by the editors and conference program committee. Some conference presentations may not be available for publication. The papers published in these proceedings reflect the work and thoughts of the authors and are published herein as submitted. The publisher is not responsible for the validity of the information or for any outcomes resulting from reliance thereon.

Please use the following format to cite material from this book:

Author(s), "Title of Paper," in 4th International Symposium on Advanced Optical Manufacturing and Testing Technologies: Design, Manufacturing, and Testing of Micro- and Nano-Optical Devices and Systems, edited by Sen Han, Masaomi Kameyama, Xiangang Luo, Proceedings of SPIE Vol. 7284 (SPIE, Bellingham, WA, 2009) Article CID Number.

ISSN 0277-786X

ISBN 9780819475442

Published by

SPIE

P.O. Box 10, Bellingham, Washington 98227-0010 USA

Telephone +1 3606763290 (Pacific Time) · Fax +1 3606471445

SPIE.org

Copyright ( 2009, Society of Photo-Optical Instrumentation Engineers

Copying of material in this book for internal or personal use, or for the internal or personal use of specific clients, beyond the fair use provisions granted by the U.S. Copyright Law is authorized by SPIE subject to payment of copying fees. The Transactional Reporting Service base fee for this volume is $\$ 18.00$ per article (or portion thereof), which should be paid directly to the Copyright Clearance Center (CCC), 222 Rosewood Drive, Danvers, MA 01923. Payment may also be made electronically through CCC Online at copyright.com. Other copying for republication, resale, advertising or promotion, or any form of systematic or multiple reproduction of any material in this book is prohibited except with permission in writing from the publisher. The CCC fee code is 0277-786X/09/\$18.00.

Printed in the United States of America.

Publication of record for individual papers is online in the SPIE Digital Library.

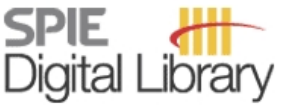

SPIEDigitalLibrary.org

Paper Numbering: Proceedings of SPIE follow an e-First publication model, with papers published first online and then in print and on CD-ROM. Papers are published as they are submitted and meet publication criteria. A unique, consistent, permanent citation identifier (CID) number is assigned to each article at the time of the first publication. Utilization of CIDs allows articles to be fully citable as soon they are published online, and connects the same identifier to all online, print, and electronic versions of the publication. SPIE uses a six-digit CID article numbering system in which:

- The first four digits correspond to the SPIE volume number.

- The last two digits indicate publication order within the volume using a Base 36 numbering system employing both numerals and letters. These two-number sets start with $00,01,02,03,04$, $05,06,07,08,09,0 A, 0 B \ldots 0 Z$, followed by 10-1Z, 20-2Z, etc.

The CID number appears on each page of the manuscript. The complete citation is used on the first page, and an abbreviated version on subsequent pages. Numbers in the index correspond to the last two digits of the six-digit CID number. 


\section{Contents}

vii Conference Committee

ix Symposium Committees

xi Introduction

\section{SESSION 4-1}

728402 Characterizations of displaying magnetic-fluid microelectromechanical light modulator with laser speckle technique [7284-01]

X. Wang, Changchun Institute of Optics, Fine Mechanics and Physics (China); D. Li, Changchun Institute of Optics, Fine Mechanics and Physics (China) and Graduate School of the Chinese Academy of Sciences (China); Y. Wang, Xi-an Institute of optics and Fine Mechanics (China); S. Su, Changchun Institute of Optics, Fine Mechanics and Physics (China) and Graduate School of the Chinese Academy of Sciences (China); J. W. Seo, Hongik Univ. (China)

728403 New method on real-time signal correction and subdivision for grating-based nanometrology [7284-02]

F. Cheng, Y.-T. Fei, Hefei Univ. of Technology (China); K.-C. Fan, National Taiwan Univ. (Taiwan)

728404 Diamond turning microstructure optical components [7284-03]

W. Jiang, LPI Precision Optics Ltd. (Hong Kong, China)

728405 Analysis and compensation of shape distortion in UV-LIGA based on partial coherent light theory [7284-04]

M. Li, L. Shen, J. Zheng, W. Zhao, Univ of Science \& Technology of China (China)

728406 Micro-machined infrared emitter with metallic photonic crystals structure [7284-05]

F. Li, H. San, M. Cheng, Xiamen Univ. (China); X. Chen, Xiamen Univ. (China) and Vestfold Univ. College (Norway)

\section{SESSION 4-2}

728407 Highly reflective optical coatings from vacuum ultraviolet to near-infrared for micro mirrors [7284-06]

M. Yang, Wuhan Univ. of Technology (China) and Technische Univ. Berlin (Germany);

X. Tong, C. Zhou, D. Jiang, Wuhan Univ. of Technology (China)

728408 FDM study of ion exchange diffusion equation in glass [7284-07]

Z. Zhou, Y. Yang, Q. Wang, G. Sun, Southwest Univ. of Science and Technology (China)

728409 MEMS testing and applications in automotive and aerospace industries [7284-08]

Z. Ma, Ford Motor Co. (United States); X. Chen, Vestfold Univ. College (Norway) 
7284 OA Static micro-Michelson interferometer based on electro-optical effect [7284-09]

$X$. He, Changchun Institute of Optics, Fine Mechanics and Physics (China) and Graduate School of the Chinese Academy of Sciences (China); G. Jin, J. Liang, Changchun Institute of Optics, Fine Mechanics and Physics (China)

$7284 \mathrm{OB} \quad \mathrm{TiO}_{2}$ nanocrystals fabricated with hydrothermal method [7284-10]

S. Fu, S. Liu, Agricultural Univ. of Hebei (China)

7284 OC Study on laser direct writing system for $32 \mathrm{~nm}$ node [7284-1 1]

W. Jiang, Institute of Optics and Electronics (China) and Graduate School of the Chinese Academy of Sciences (China); S. Hu, Institute of Optics and Electronics (China); Y. Yang, Institute of Optics and Electronics (China) and Graduate School of the Chinese Academy of Sciences (China); L. Zhao, W. Yan, Institute of Optics and Electronics (China); S. Zhou, W. Chen, Institute of Optics and Electronics (China) and Graduate School of the Chinese Academy of Sciences (China)

POSTER SESSION

7284 OD Application of MEMS blazed gratings in WDM [7284-12]

Y. Wu, Chongqing Univ. (China) and Southwest Univ. (China); H. Yu, Z. Kang, Chongqing Univ. (China)

7284 OE Development of a 20X Schwarzschild projection optics for principle experiment of EUV at-wavelength interferometry [7284-13]

K. Liu, Institute of Electrical Engineering (China) and Graduate Univ. of the Chinease Academy of Sciences (China); Y. Li, Institute of Electrical Engineering (China) and Beijing Institute of Technology (China)

7284 OF Effects of stress on the adhesive behavior of photoresist [7284-14]

Y. Geng, W. Zhang, C. Hou, J. Bai, Zhejiang Univ. (China)

7284 OG Effect of adaptive optical system on the capability of lidar detection in atmosphere [7284-15]

X. Tan, Z. Wu, Z. Liang, Changchun Univ. of Science and Technology (China)

$7284 \mathrm{OH}$ Simulation on a deformable mirror actuated by microfluidic elements [7284-16]

C. Deng, H. Wang, Univ. of Electronic Science and Technology of China (China); W. Sun, College of Sichuan Aerospace Technology (China)

7284 ol Automatic alignment system for optical lithography based on machine vision [7284-17] T. Huang, S. Liu, P. Yi, T. Shi, Huazhong Univ. of Science and Technology (China)

7284 0J Imaging characterization and tolerance analysis of thin planar photon sieves [7284-18] Z. Chen, C. Wang, H. Qu, Soochow Univ. (China)

7284 OK System-level design and analysis of MEMS-based micro-fuze resonator [7284-19] R. Guo, D. Huang, W. Guo, D. Shi, Xi'an Univ. of Technology (China)

7284 OL Design and optimization of 2D electrostatic micro scanning mirrors [7284-20]

W. Ma, F. Hu, D. Cai, D. Wang, J. Yao, C. Qiu, Institute of Optics and Electronics (China) 
7284 OM The theoretical analysis of tri-beam SPPs interference through Ag film [7284-21]

F. Jin, Sichuan Univ. (China) and Institute of Optics and Electronics (China); J. Du, Y. Guo, Sichuan Univ. (China); L. Shi, C. Du, Institute of Optics and Electronics (China)

7284 ON Plamonic nanolens focusing light in subwavelength scale [7284-22]

H. Shi, C. Wang, C. Du, Institute of Optics and Electronics (China)

728400 Simulation of surface plasmon nanolithography using tapered structure [7284-23]

X. Wei, X. Dong, C. Du, Institute of Optics and Electronics (China)

7284 OP Micro-structuring of photonic materials by deep-ultraviolet laser [7284-24]

Y. Dai, D. Jiang, G. Xu, Wuhan Univ. of Technology (China)

$7284 \mathrm{OQ}$ Micropatterning cathode separator for high-resolution organic light-emitting diode with negative and positive type photoresists [7284-25]

J. Wang, J. YU, Y. Jiang, K. Yuan, Univ. of Electronic Science and Technology of China (China)

7284 OR Method of laser mode selection based on silicon micro F-P cavity [7284-26]

Z. Wu, X. Tan, M. Ling, Z. Wu, G. Jin, Z. Liang, Changchun Univ. of Science and Technology (China)

7284 OS Study on enhancing dynamic range of CCD imaging based on digital micro-mirror device [7284-27]

W. Zhou, Soochow Univ. (China)

7284 OT Numerical simulations of volume holographic imaging system resolution characteristics [7284-28]

Y. Sun, Z. Jiang, S. Liu, S. Tao, Beijing Univ. of Technology (China)

7284 OU Rim morphology of nanopore for studying single biomolecule [7284-29]

K. Wang, Northwest Univ. (China) and Shenzhen Univ. (China); Q. Li, Northwest Univ. (China);

G. XU, A. Jin, Shenzhen Univ. (China); C. Gu, Institute of Physics (China)

7284 OV Application of support vector machines in the micro spectrometer [7284-30]

Y. Xiong, Nanchang Univ. (China) and Chongqing Univ. (China); Z. Wen, Chongqing Univ.

(China); S. Xu, F. Ye, Nanchang Univ. (China)

7284 OW Interaction between femtosecond laser and silicon nitride crystal film [7284-31]

W. Zhang, K. Wang, J. Bai, Z. Ren, Northwest Univ. (China)

7284 OX Influence of non-ideal lens array on position and quality of 3D reconstruction in integral images [7284-32]

H. Wang, Y. Yang, C. Wu, Q. Wang, Univ. of Science and Technology Beijing (China)

7284 OY Design of optical coherence tomography probe using a 2-axis MEMS scanning mirror [7284-33]

D. Wang, G. Shi, Institute of Optics and Electronics (China); Z. Li, Institute of Optics and Electronics (China) and Univ. of Electronic Science and Technology of China (China);

D. Cai, J. Yao, T. Fan, Institute of Optics and Electronics (China) 
$7284 \mathrm{OZ}$ Increasing the sensitivity of Love wave sensors with thicker waveguide layer by modified spin coating method [7284-34]

J. Hu, X. Du, G. Xie, P. Sun, Y. Jiang, Univ. of Electronic Science and Technology of China (China)

728410 Fabrication and gas sensitivity of poly-2,5-dimethoxyethynylbenzene/ $/ \mathrm{SnO}_{2}$ nanocomposite [7284-35]

P. Sun, Univ. of Electronic Science and Technology of China (China) and Sichuan

Agricultural Univ. (China); Y. Jiang, G. Xie, J. YU, Y. YU, J. Hu, Univ. of Electronic Science and Technology of China (China)

$728411 \quad$ Fabrication and emission properties of LaB 6 field emission microtriodes [7284-36]

X. Wang, Y. Jiang, Z. Lin, K. Qi, J. Dong, Univ. of Electronic Science and Technology of China (China)

728412 Improved near-field lithography by surface plasmon resonance [7284-37]

B. Zeng, Y. Zhao, L. Fang, C. Wang, X. Luo, Institute of Optics and Electronics (China)

728413 Fabrication of flexible grating sensing waveguide based on nano-imprint lithography and micro-replication process [7284-38]

Y. Liu, China Jiliang Univ. (China); W. Tian, Xi'an Institute of Optics and Precision Mechanics (China); S. Zhang, China Jiliang Univ. (China)

728414 Nano-materials analysis using optical profiler [7284-39]

D. Ge, Y. Li, Harbin Institute of Technology (China); S. Han, Veeco Instruments Inc. (United States); L. Yang, Harbin Institute of Technology (China)

728415 Effect of substrate bending on the piezoelectric measurement of PZT thin film [7284-40] X. XU, J. Tang, Jiangxi Electronic Power Research Institute (China); L. He, Ohio State Univ. (United States)

728416 SWS grating for UV band filter by nano-imprint [7284-41]

J.-S. Lin, K.-H. Liao, Industrial Technology Research Institute (Taiwan); C.-T. Chen, Yuan Ze Univ. (Taiwan); C.-L. Lai, Industrial Technology Research Institute (Taiwan); C.-H. Ko, Yuan Ze Univ. (Taiwan)

728417 Research on digital gray-tone projection lithography [7284-42]

J. Wang, L. Zhao, W. Yan, W. Xu, S. Hu, X. Tang, Z. Wang, S. Wang, Z. Zhang, Institute of Optics and Electronics (China)

728418 Near-field diffraction simulation on three-dimensional mask model with off-axis illumination [7284-43]

L. Cheng, P. Cao, J. Liu, X. Zhang, Lanzhou Univ. (China)

Author Index 


\title{
Conference Committee
}

\author{
Conference Chairs
}

Sen Han, Veeco Metrology, Inc. (United States)

Masaomi Kameyama, Nikon Corporation (Japan)

Xiangang Luo, Institute of Optics and Electronics, CAS (China)

Program Committee

Xiangchao Wang, Shanghai Institute of Optics and Fine Mechanic,

CAS (China)

Zhihong Li, MEMS Center, Beijing University (China)

Li-Anne Liew, National Institute of Science and Technology (United States)

Ming Liu, Institute of Microelectronics, CAS (China)

Yao Li, Centre for Composite Materials, Harbin Institute of Technology (China)

Tadashi Hatano, Tohoku University (Japan)

Zhichun Ma, Michigan Aerospace Corporation (United States)

Xiaoping Li, Shanghai Micro-Electronic Equipment Company, Ltd. (China)

Sung Moon, Korean Institute of Science and Technology (Korea)

Qingliang Zhao, Harbin Institute of Technology (China)

Fengzhou Fang, Tianjin University (China)

\section{Session Chairs}

4-1 Xiangang Luo, Institute of Optics and Electronics, CAS (China)

4-2 Jun Yao, Institute of Optics and Electronics, CAS (China) 
Downloaded From: https://www.spiedigitallibrary.org/conference-proceedings-of-spie on 26 Apr 2023

Terms of Use: https://www.spiedigitallibrary.org/terms-of-use 


\section{Symposium Committees}

Honorary Chair

Daheng Wang, Chinese Academy of Sciences (China) and Chinese Academy of Engineering (China)

Symposium General Chair

Bingkun Zhou, Chinese Optical Society (China) and Chinese Academy of Sciences (China)

Symposium General Cochairs

James C. Wyant, College of Optical Sciences, The University of Arizona (United States)

Jianlin Cao, Ministry of Science and Technology of China (China)

Yudong Zhang, Institute of Optics and Electronics, CAS (China)

Organizing Committee

Yudong Zhang, Chair, Institute of Optics and Electronics, CAS (China)

Jinghua Cao, Cochair, Bureau of International Cooperation, CAS (China)

Guoqiang Ni, Cochair, Chinese Optical Society (China)

Jos Benschop, ASML (Netherlands)

John M. Schoen, University of Rochester (United States)

Edgar Bader, Carl Zeiss SMT AG (Germany)

Li Yang, Committee of Optical Manufacturing Technology, COS (China)

Jinxue Wang, SPIE

Eric Ruch, REOSC Optics, SAGEM (France)

James H. Burge, College of Optical Sciences, The University of Arizona (United States)

David D. Walker, University College London (United Kingdom)

Yoshiharu Namba, Chubu University (Japan)

Hexin Wang, Carl Zeiss Jena AG (Germany)

Masaomi Kameyama, Nikon Corporation (Japan)

Fan Wu, Institute of Optics and Electronics, CAS (China)

Rongbin Li, Hong Kong Polytechnic University (Hong Kong, China)

Tadashi Hatano, Tohoku University (Japan)

Jingzhen Li, Shenzhen University (China)

Mike DeMarco, QED Technologies (United States)

James R. Torley, University of Colorado at Colorado Springs

(United States)

Xiaoping Li, Shanghai Micro-Electronic Equipment Company, Ltd. (China)

Robert Smythe, ZYGO Corporation (United States)

Richard Freeman, ZEEKO Ltd. (United Kingtom)

Gavin F. Chapman, Moore Precision Tools (United States) 
Program Committee

Hu Yang, Chair, Institute of Optics and Electronics, CAS (China)

Yuwen Qin, Cochair, Natural Science Foundation of China (China)

Sen Han, Cochair, Veeco Metrology Inc. (United States)

Myung K. Cho, Cochair, National Optical Astronomy Observatory (United States)

Bernard Delabre, European Southern Observatory (Germany)

Huadong Yu, Changchun University of Science and Technology (China)

Magomed A. Abdulkadyrov, Lytkarino Optical Glass Factory (Russian Federation)

Jose M. Sasian, College of Optical Sciences, The University Arizona (United States)

Ming Liu, Institute of Microelectronics, CAS (China)

Qiming Xin, Beijing Institute of Technology (China)

Wei Li, Chengdu Fine Precision Optical Engineering Research Center (China)

Paul Kloceck, ELCAN Optical Technologies (United States)

Jingchi Yu, Suzhou University (China)

Xuemin Cheng, Tsinghua University (China)

Xuejun Zhang, Changchun Institute of Optics, Fine Mechanics and Physics, CAS (China)

Mary G. Turner, InfoTek Information Systems (United States)

Changyuan Han, Optical Testing Technology Committee, COS (China)

Masahide Katsuki, Toshiba Machine Company, Ltd. (Japan)

Ying Chun Liang, Harbin Institute of Technology (China)

Matthias Pfaff, OptoTech Optikmaschinen GmbH (Germany)

Michael Sander, Satisloh GmbH (Germany)

Thomas Danger, Schneider GmbH \& Company KG (Germany)

Michael Conroy, Taylor Hobson Ltd. (United Kingdom)

Secretary General of the Symposium

Li Yang, Committee of Optical Manufacturing Technology, COS (China) Jinxue Wang, SPIE (United States) 


\section{Introduction}

Optical manufacturing technology has achieved tremendous progress, especially during the last 20 years both in China and abroad. To meet the demand of the development in this area, AOMATT-International Symposium on Advanced Optical Manufacturing and Testing Technology has been held four times from 2000 to 2008. The 4th International Symposium on Advanced Optical Manufacturing and Testing Technology (AOMATTO8) was held at Wang Jiang Hotel in Chengdu, China, 19-21 November 2008. A total of 381 papers have been selected for publication in the Proceedings of SPIE volumes 7281, 7282, 7283 and 7284, corresponding to the four conferences of AOMATT08: Large Mirrors and Telescopes; Advanced Optical Manufacturing Technologies; Optical Test and Measurement Technology and Equipment; and Design, Manufacturing, and Testing of Micro- and Nano-Optical Devices and Systems. We have faced many challenges during the organization of AOMATT08. They include the big Sichuan Wenchuan earthquake on 12 May 2008, the worldwide financial crisis, and the deepening recession in many countries around the world. These challenges and difficulties have negatively impacted the number of papers and attendees for AOMATT08. The number of accepted papers decreased from 485 for AOMATT07 to 381 for AOMATT08. However, conference quality has continued to improve. Based on comments from authors and attendees, significant improvements have been made in conference organization, the opening ceremony, quality of the plenary presentation, oral presentations, workshops, and the closing ceremony, etc. A more important fact is the continued improvement in the quality of the papers published in the Proceedings of SPIE. Many papers report cutting-edge research and development; more authors are from famous universities, research institutions, and leading enterprises around the world. Authors and attendees had the opportunity to exchange ideas and learn from each other at the conference.

We are delighted that each AOMATT symposium is more successful than the previous one. It has become a well-established symposium covering advanced optical manufacturing and testing technologies, and has attracted a loyal following in academy and industries around the world. Our goal is to develop AOMATT into a must-attend international symposium for the optical manufacturing and testing community. We would like to express our sincere appreciation to COS-The Chinese Optical Society, IOE-Institute of Optics and Electronics, Chinese Academy of Sciences, and to SPIE for sponsoring AOMATT08. We want to thank authors and attendees for attending the symposium and sharing their research with their colleagues around the world. We especially thank IOE and Dr. Yudong Zhang, President of IOE, for hosting AOMATTO8 and the tremendous hospitality during the conference.

The world is in the middle of significant financial and economic crisis. Crisis often brings difficulties and opportunities at the same time. Many countries have 
announced economic stimulus measures. The Chinese government has promised 600 billion Yuan RMB to six key national projects. Several projects are closely related to optical manufacturing and testing technology and equipments and represent opportunities for researchers and enterprises around the world. New discoveries and products will emerge as a result. We are looking forward to seeing you all at the AOMATT 2010 in China, please watch the SPIE and IOE websites for call for papers and exact time and locations.

Li Yang

Secretary General, AOMATT 2008

Chairman, Committee on Optical Manufacturing Technology (COMT), COS 